\title{
How to value protection from natural hazards - a step-by-step discrete choice approach
}

\author{
R. Olschewski \\ WSL Swiss Federal Research Institute, Environmental and Resource Economics, Zürcherstrasse 111, \\ 8903 Birmensdorf, Switzerland
}

Correspondence to: R. Olschewski (roland.olschewski@wsl.ch)

Received: 18 September 2012 - Published in Nat. Hazards Earth Syst. Sci. Discuss.: Revised: 8 March 2013 - Accepted: 12 March 2013 - Published: 12 April 2013

\begin{abstract}
In mountainous regions, forests play a crucial role in protecting the local population from natural hazards. In cases where existing forests are destroyed, e.g. by wind throws or diseases, the protection function has to be restored through technical measures. To determine the willingness to pay (WTP) for protection against avalanches, a choice experiment has been conducted and different experiment specifications have been tested to determine possible impacts on the results. The present study contributes to a comprehensive assessment of protection measures, and helps to identify efficient solutions based on the judgement of the people potentially endangered by natural hazards. The stepwise approach has the advantage to gradually check data fit, thereby didactically showing an operational way of dealing with different model specifications. The detailed case study can serve as a manual for conducting choice experiments with a similar focus and demonstrates the suitability and caveats of this approach to value protection from natural hazards in general.
\end{abstract}

\section{Introduction}

Avalanche protection is one of the most important functions of forests in mountainous regions. However, natural hazards caused by extreme weather events and climate change might reduce the ability of forests to provide this public service. Once the forest is destroyed, alternative measures have to be taken to reduce risk and to prevent the local population and infrastructure from costly damages. In this situation, it is helpful for governmental authorities to know which protection alternatives are technically available, and how protection services and the respective measures are evaluated by the population affected. This is especially true in Switzerland, where decisions are often based on ballots held at the municipality level.

From an economic point of view, decision support can be provided based on efficiency criteria, where benefits of protection are compared with the costs of measures against natural hazards. One survey technique to determine the population's benefits from protection services is the so-called choice experiment (CE), which has been applied in marketing research for a long time (Green and Srinivasan, 1990; Grover and Vriens, 2006; Wierenga, 2008). Recently, CE has become the state-of-the art technique of non-market valuation in environmental economics. Here, manifold ecosystem services, such as biodiversity conservation, carbon sequestration or recreation, have been subject to monetary valuation studies. However, only a few case studies have applied this stated preference approach to valuing natural hazard mitigation (see e.g. Rheinberger, 2009; Leiter and Pruckner, 2009).

Following the typical CE procedure, respondents are first made familiar with a certain scenario, in this case the scenario related to the danger of a village of being hit by an avalanche (Fig. 1).

In a second step respondents are confronted with several options of being protected against avalanches. These options are characterised by different attributes such as the damage to be avoided, the duration of the project or the related costs. Then, the respondents have to choose their preferred protection alternative. Based on this information, the importance of specific attributes can be determined and trade-offs between these attributes can be analysed.

When conducting a choice experiment it is crucial to develop a realistic scenario and an appropriate attribute design 


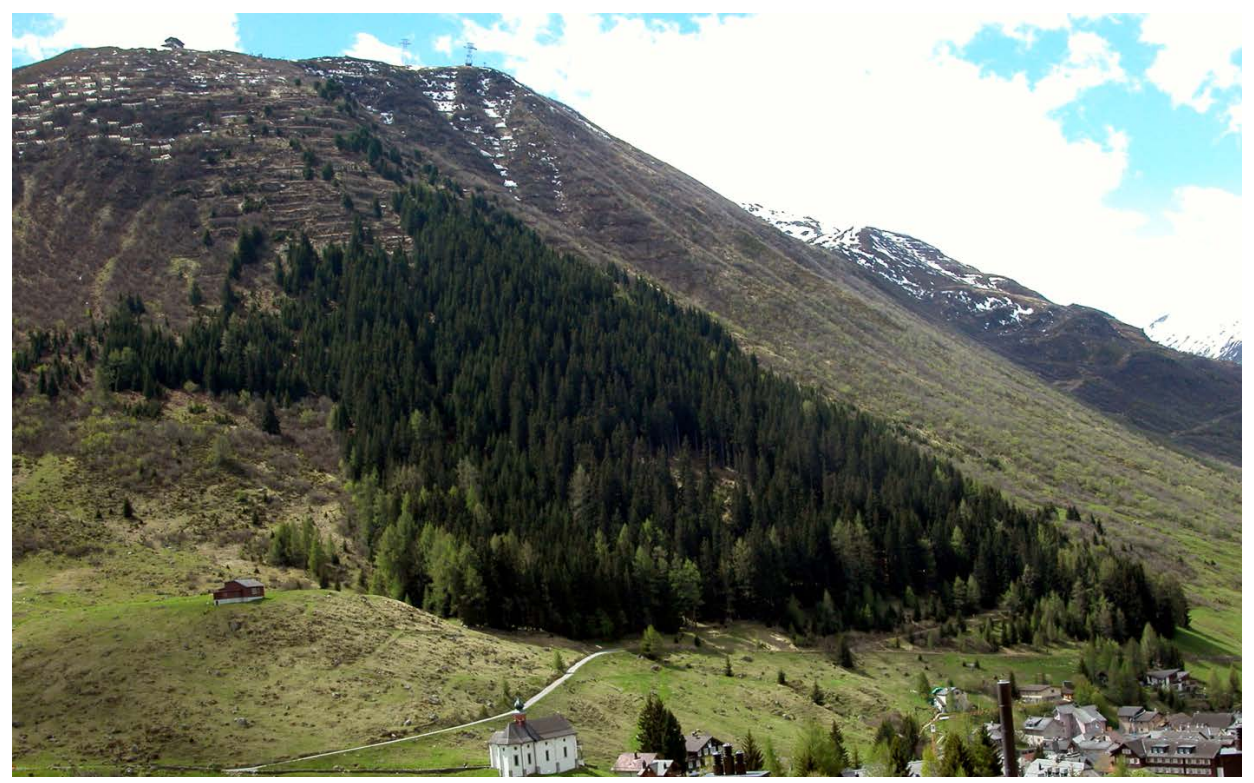

Fig. 1. Protection forest of Andermatt (CH) (photo: P. Brang, WSL).

to reduce the cognitive burden on the respondents to process the provided information (Hoyos, 2010). For the present study, a scenario has been chosen in which a wind throw had partly destroyed a protection forest and alternative technical measures have to be established (Olschewski et al., 2011). These measures include wooden stems and grills as well as steel bridges and nets, which are established in the slope as avalanche barriers (compare Fig. 2a-d). In the survey all measures were described in detail based on five attributes and visualised with photos. The aim of the experiment was to estimate the willingness to pay (WTP) for restoring protection from avalanches and to find out, which protection measure is the preferred one.

In this paper, the impact of using a so-called labelled experiment on preference and willingness-to-pay estimates is analysed. After providing the methodological background, the results of the original experiment are briefly presented. The main part of the paper deals with the elaboration of alternative ways to analyse the gathered data and their impact on the results. Finally, the approaches are compared and some implications for the design of choice experiments are discussed.

\section{Methods}

\subsection{Choice experiments}

The originally applied version of the CE is based on a multinomial logit model (MNL), i.e. a regression model used to predict the probabilities of discrete outcomes based on a set of independent variables. These independent variables are called attributes and are comprised of "damage avoidance" (DA), "duration" (DU), "starting time" (ST), "costs"
(CO) and "type of protection measure" (TY). Each attribute has three numerical levels, except "type", which consists of technical protection measures: wooden stems, wooden grills, steel bridges, and steel nets (compare Table 1). To take this particularity into account, the respective "types" have been specified as a categorical attribute using dummy variables.

All five attributes and their respective levels have been combined in three unlabelled options (A, B, C) in so-called choice sets (compare Fig. 3). The way the attribute levels are arranged is determined by the "design" of the CE. According to Huber and Zwerina (1996) four principles can be followed to achieve an efficient choice experiment design: orthogonality, level balance, minimal overlap, and utility balance. Given that it is not possible to create a design that satisfies all principles, the short-cut method has been chosen, which ensures minimal overlap (Sawtooth, 2008). This means each option is built by choosing attribute levels least frequently applied in previous options to keep the alternatives in any task as different from one another as possible (Olschewski et al., 2012). Chrzan and Orme (2000) conduct a comparison of several full factorial and randomised design strategies and find that the short-cut method is ideally suited for the estimation of main effects and alternative specific attributes, while capturing a maximum of informational content. The statistical analysis has been conducted based on 120 different generated choice sets using the "BIOGEME"-software (Bierlaire, 2003, 2008).

All 488 households in the study region Andermatt $(\mathrm{CH})$ have been invited in writing to take part in an internet survey, with the proviso that only one person per household can participate. This member must have a minimum age of 18 and usually take financial decisions for the household. 

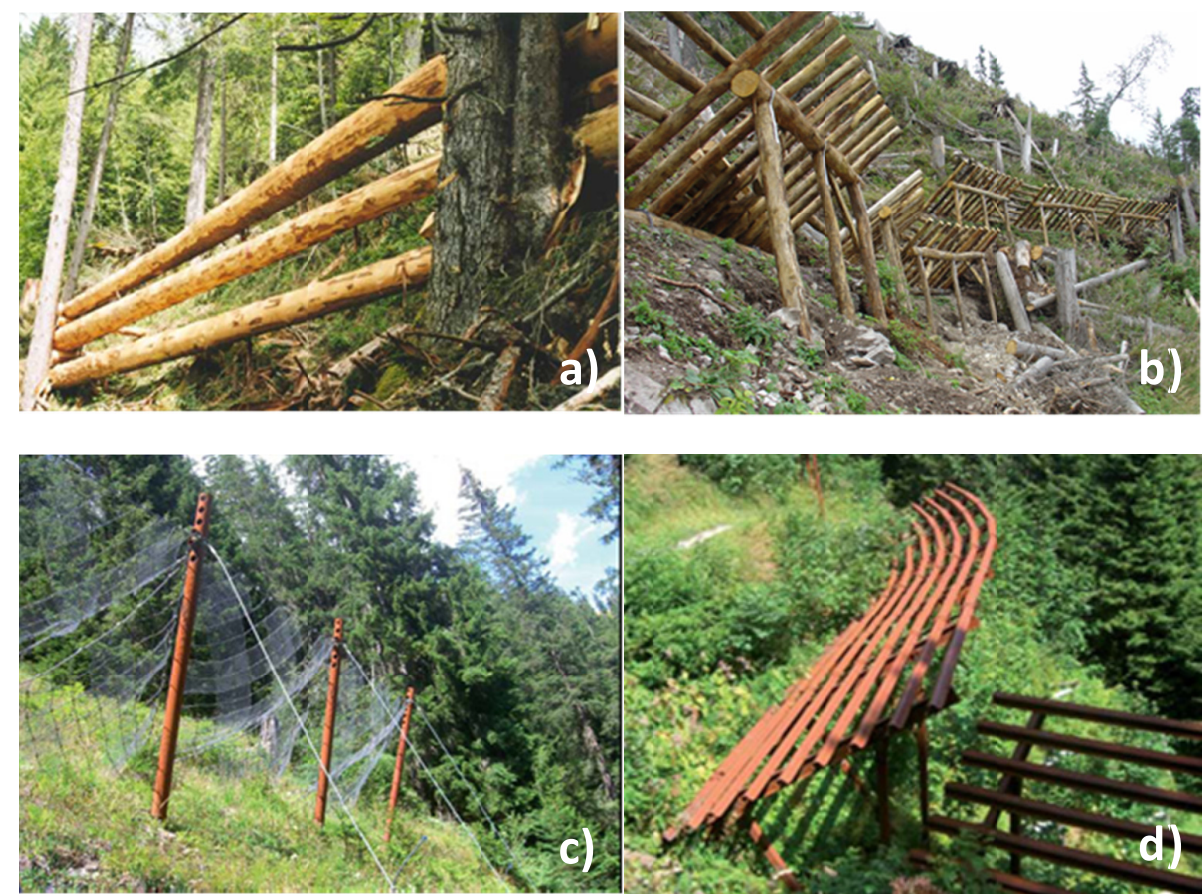

Fig. 2. Avalanche protection measures: (a) wooden stems, (b) wooden grills, (c) steel nets, and (d) steel bridges. (Photos (a) and (b): Forestry Department of Canton Berne, Natural Hazards Division, Interlaken.)

Table 1. Choice experiment attributes with numerical and categorical levels.

\begin{tabular}{lcccc}
\hline Attributes & \multicolumn{4}{c}{ Levels } \\
\hline Damage avoidance (DA; \%) & $50-60-70$ & $60-70-80$ & $70-80-90$ & $70-80-90$ \\
Duration (DU; yr) & $15-20-25$ & $20-25-30$ & $60-70-80$ & $60-70-80$ \\
Starting time (ST; yr) & $1-3-5$ & $1-3-5$ & $1-3-5$ & $1-3-5$ \\
Costs (CO; CHF) & $100-150-200$ & $200-250-300$ & $400-500-600$ & $400-500-600$ \\
Type (TY) & Wooden stems & Wooden grills & Steel nets & Steel bridges \\
\hline
\end{tabular}

* All calculations have been made in CHF. Estimates have been transformed into USD at a $1: 1$ exchange rate (CHF/USD), which approximates the average exchange rate in 2010 (compare Olschewski et al., 2012).

Each respondent had to select one out of three options from ten successive choice sets (compare Fig. 3). Louviere et al. (2000) state that it often makes sense to include a "no choice" option to add realism and to estimate true demand models. However, in our particular case the authorities are legally required to protect the local population through natural or technical measures, which are financed - at least partly - by the population itself. As a result, residents actually do not have the opportunity to opt out. Thus recognizing that choices are made under this condition, it is adequate to neglect the opt-out alternative in the choice sets.

It is assumed that the respondents are utility maximising individuals. Their behaviour is analysed based on random utility theory, where the utility $U$ of an alternative $i$ for an individual $n$ consists of an observable component $V$, which is given by the attributes described above, and an unobserved random component $\varepsilon$ (Louviere, 2001).

$U_{n i}=V_{n i}+\varepsilon_{n i}$

In a first step, the unobserved components $\varepsilon_{n i}$, are supposed to be independent and to have the exact same distribution, i.e. $\varepsilon_{n i}$ are independently and identically "extreme value" distributed (iid) (Hensher et al., 2005). The basic specification of the observable component of the utility function is given by Eq. (2)

$$
\begin{aligned}
V_{n i}= & \beta_{1} \cdot D A_{n i}+\beta_{2} \cdot D U_{n i}+\beta_{3} \cdot S T_{n i}+\beta_{4} \cdot C O_{n i} \\
& +\beta_{5(\mathrm{~B}, \mathrm{G}, \mathrm{N})} \cdot T Y_{n i} .
\end{aligned}
$$

Note that the coefficients of the explanatory variables $\left(\beta_{1}, \beta_{2}\right.$, $\beta_{3}$, and $\beta_{4}$ ) are generic, i.e. they do not vary among alternatives. In contrast, the coefficients $\beta_{5(\mathrm{~B}, \mathrm{G}, \mathrm{N})}$ of the categorical variable "type" vary among alternatives, thereby indicating 


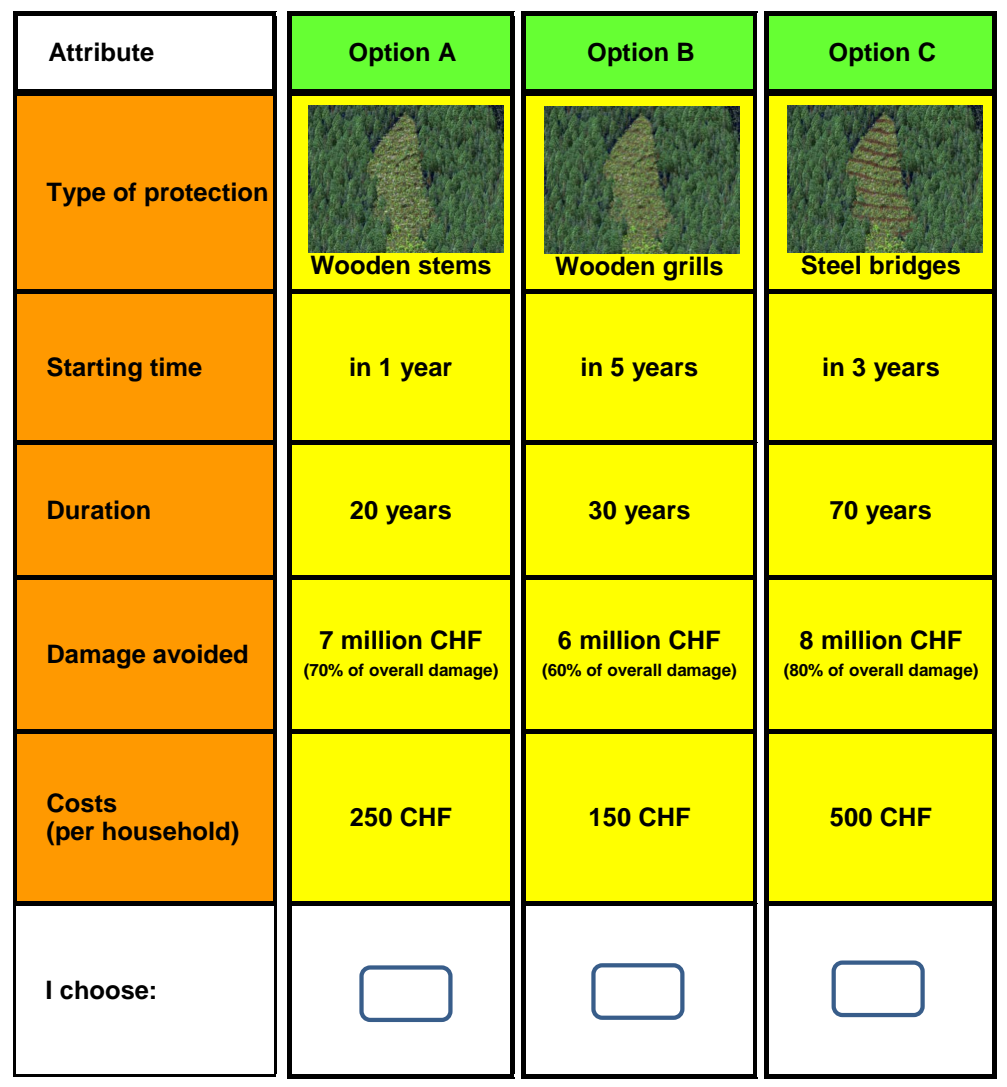

Fig. 3. Example of a choice set (by clicking on the images the respondents were able to enlarge the visualisations of the wind throw area with the respective protection measures. All choice sets have been presented in CHF. Estimates have been transformed into USD at a $1: 1$ exchange rate (CHF/USD), which approximates the average exchange rate in 2010 (compare Olschewski et al., 2011).

respondents preferences towards different types of protection measures. To capture these preferences, dummy variables for all types but one are included (bridges, grills, nets), while the type "stems" is excluded and serves as a baseline (Hensher et al., 2005).

The probability that a respondent prefers alternative $i$ over alternative $j$ can be expressed as follows (compare Train, 2003):

$P_{n i}=\operatorname{Prob}\left(V_{n i}+\varepsilon_{n i}>V_{n j}+\varepsilon_{n j} \forall j \neq i\right)$

$P_{n i}=\operatorname{Prob}\left(\varepsilon_{n j}-\varepsilon_{n i}<V_{n i}-V_{n j} \forall j \neq i\right)$.

Given that $\varepsilon$ is iid distributed, Eq. (5) determines the probability of alternative $i$ of being chosen:

$P_{n i}=\frac{e^{V_{n i}}}{\sum_{j} e^{V_{n j}}}$.

\subsection{Labelling}

Hensher et al. (2005) distinguish between "authentic real world data" and "perceptual data", and emphasize that choice decisions are more likely to be the result of "perceptual belief". This raises the question, how do respondents perceive certain attributes when making choices. Although originally designed as an unlabelled experiment, where respondents have to choose between generic options $\mathrm{A}, \mathrm{B}$, and $\mathrm{C}$, there was evidence that the respondents might have perceived and interpreted one specific attribute, namely "type", as a label for the respective options within a choice set. An analysis of the debriefing survey questions showed that aspects of landscape beauty have played a major role when making choices. In all, $75 \%$ of the respondent said that aesthetical aspects have been important when choosing an option within a choice set.

Given these descriptive findings, one can conclude that the respondents might have put relatively more emphasis on the aesthetics-related attribute "type", thereby not perceiving it as one attribute among others, but unconsciously using it as an overall label for the presented options. Therefore, alternative-specific aspects have to be analysed in more detail. For this purpose, the utility function has been adapted (i) by specifying the observable component $V$ in correspondence to the respective protection measure, and (ii) by including alternative specific constants (ASC) in the utility functions (compare Eqs. 6-9). These constants capture 
variation in choices that cannot be explained by the observable components (Bennett and Adamowicz, 2001). Here, ASC are coded with the value " 1 " in case of appearance of the respective types (bridges, grills, ...), and "0" otherwise. Since for comparison only differences in utility matter, alternative specific constants are included in all equations but one (Train, 2003). Note that the coefficients of the explanatory variables $\left(\beta_{1}-\beta_{4}\right)$ remain generic, i.e. they do not vary among alternatives (compare Hensher et al., 2005), while the categorical attribute "type" now serves as a label for the presented alternatives, and thus, the respective coefficients $\left(\beta_{5}(\mathrm{~B}, \mathrm{G}, \mathrm{N})\right)$ are omitted in this specification.

$$
\begin{aligned}
& V_{\text {bridges }}=\mathrm{ASC}_{\text {bridges }}+\beta_{1} \cdot \mathrm{DA}_{\text {bridges }}+\beta_{2} \cdot \mathrm{DU}_{\text {bridges }} \\
& +\beta_{3} \cdot \mathrm{ST}_{\text {bridges }}+\beta_{4} \cdot \mathrm{CO}_{\text {bridges }} \text {, } \\
& V_{\text {grills }}=\mathrm{ASC}_{\text {grills }}+\beta_{1} \cdot \mathrm{DA}_{\text {grills }}+\beta_{2} \cdot \mathrm{DU}_{\text {grills }} \\
& +\beta_{3} \cdot \mathrm{ST}_{\text {grills }}+\beta_{4} \cdot \mathrm{CO}_{\text {grills }} \text {, } \\
& V_{\text {nets }}=\mathrm{ASC}_{\text {nets }}+\beta_{1} \cdot \mathrm{DA}_{\text {nets }}+\beta_{2} \cdot \mathrm{DU}_{\text {nets }}+\beta_{3} \cdot \mathrm{ST}_{\text {nets }} \\
& +\beta_{4} \cdot \mathrm{CO}_{\text {nets }} \text {, } \\
& V_{\text {stems }}=\beta_{1} \cdot \mathrm{DA}_{\text {stems }}+\beta_{2} \cdot \mathrm{DU}_{\text {stems }}+\beta_{3} \cdot \mathrm{ST}_{\text {stems }} \\
& +\beta_{4} \cdot \mathrm{CO}_{\text {stems }} \text {. }
\end{aligned}
$$

This adaptation permits to iteratively test further model specifications and different nesting structures in order to compare them with the results of the unlabelled model.

\subsection{Nested-logit model}

The standard logit approach fulfils the requirement of the independence from irrelevant alternatives (IIA). This property can easily be derived when considering the ratio of two probabilities $P_{n i}$ and $P_{n k}$ (compare Train, 2003):

$$
\begin{gathered}
P_{n i}=\frac{e^{V_{n i}}}{\sum_{j} e^{V_{n j}}} \\
P_{n k}=\frac{e^{V_{n k}}}{\sum_{j} e^{V_{n j}}} \\
P_{n i} / P_{n k}=\frac{e^{V_{n i}}}{e^{V_{n k}}} .
\end{gathered}
$$

Equation (12) shows that the ratio only depends on the alternatives $i$ and $k$, i.e. all other alternatives are irrelevant. The logit model exhibits this characteristic by definition due to the underlying probability function. However, it is seldom possible to capture all types of correlation among alternatives, and a label might even aggravate this problem, when perceived as an attribute of an entire choice option. In this case an alternative behavioural model, e.g. a nested approach, can be applied.

Nesting means to assign alternatives to certain subcategories or "nests" based on similarities between random components associated with different alternatives. Often, it is hardly possible to determine these similarities, thereby im- peding to build nests a priori. In the present study the following characteristics facilitated the composition of nests: on the one hand nests could be determined based on the timerelated characteristics of the protection measures: temporary wooden versus permanent steel solutions. On the other hand a distinction can be made based on aesthetical aspects given that wooden logs and grills are less visible in the landscape than steel nets or bridges, thereby having less impact on scenic beauty. A closer look at the supporting survey questions confirms this aspect. Besides the choice sets, the households were asked, which measure would be their first choice based on aesthetical aspects. About $46 \%$ selected wooden grills and about $39 \%$ wooden logs as their first choice, respectively. Accordingly, the most appropriate specification for the further analysis was considered to be given by wooden and steel measures in two different nests.

\subsection{Willingness-to-pay analysis}

The $\beta$ coefficients to be estimated in Eqs. (2) and (6)-(9) indicate by their respective sign, whether an attribute has a positive or negative impact on utility. Furthermore, they can be used to identify trade-offs the respondents are willing to make between different attributes. In case that one of the attributes is expressed in monetary terms, these trade-offs can be determined as "part-worth" or "implicit price" of changes in attribute levels (Bennett and Adamowicz 2001). Note that these estimates represent the willingness to pay for an increase or decrease of an attribute depending on the sign and under the assumption that all other things remain equal (Alberini et al., 2006). The rationale of this statement becomes clear, when looking at the derivative of the utility function with respect, e.g. to "damage avoidance" (compare Eqs. 1315):

$$
\begin{aligned}
& \mathrm{d} U=\frac{\partial U}{\partial \mathrm{DA}} \cdot \mathrm{dDA}+\frac{\partial U}{\partial \mathrm{CO}} \cdot \mathrm{dCO}=\beta_{1} \cdot \mathrm{dDA} \\
& +\beta_{4} \cdot \mathrm{dCO} \stackrel{!}{=} 0 \\
& -\frac{\beta_{1}}{\beta_{4}}=\frac{\mathrm{dCO}}{\mathrm{dDA}} \\
& \mathrm{WTP}=\mathrm{dCO}=-\frac{\beta_{1}}{\beta_{4}} \cdot \mathrm{DA} .
\end{aligned}
$$

Note that in this case WTP for damage avoidance is determined irrespective of the type of protection measure. Consequently, it can also be applied to a scenario, where protection is naturally provided by forests instead of technical solutions (Olschewski et al., 2012). In addition, WTP for specific protection measures can be estimated based on the respective coefficients for the categorical attribute "type". 


\section{Results}

\subsection{Unlabelled experiment}

The left part of Table 2 shows the results of the unlabelled model specification based on 129 completed questionnaires, i.e. 1290 observations. Most of the estimated generic coefficients $\left(\beta_{1}-\beta_{4}\right)$ have the expected sign. Costs have a negative coefficient, because payments reduce the households' budget, thereby decreasing utility. Damage avoidance has a positive sign, because protection from damages increases utility, whereas delaying starting time has negative impact, because longer waiting time without protection reduces utility. Interestingly, duration (though not significant) has a negative sign, denoting reduced preferences for longer-lasting protection measures. Finally, the estimated "type" coefficients have a positive sign indicating that bridges and grills are preferred compared to "stems", while nets are not significantly different from this baseline.

To achieve additional information and adequately interpret these findings, Krupnick and Adamowicz (2006) highlight the relevance and support of briefing and debriefing survey questions, e.g. for identifying strategies individuals use to simplify choice decisions. Here, this aspect is of special interest, because a majority of about $75 \%$ of the respondents declared that aesthetical aspects played an important role when deciding which option to choose, while only about $10 \%$ said that the particular type of protection measure was not important when comparing the different options in the choice sets (Olschewski et al., 2012). Therefore, the following analysis is focussed on the attribute "type" by reestimating the model based on a labelled specification.

\subsection{Labelled experiment}

The results provided by the supporting questions raised the following problem: What, if the respondents have perceived the originally unlabelled experiment as a labelled one by taking the attribute "type" as an overall label for the respective options in each choice set?

In the middle part of Table 2, the results of the adapted multi-nomial logit model are shown, which now includes alternative specific constants for the respective types of measures (compare Eqs. 6-9). In addition to the unlabelled experiment, the new specification allows for a complementary and differentiated analysis. The estimated ASC coefficients support the findings of the unlabelled model, as far as the significant positive preference for wooden grills is concerned. However, steel bridges are no longer significant compared to stems, while the coefficient for nets is now significantly different from zero. In comparison to the unlabelled model, all other coefficients, while slightly changing their magnitude, remain significant (except duration) and maintain their respective sign.
Given these results the question arises, which model is superior in fitting the data. Here, log-likelihood (LL) estimations provide some insight: the final LL value of the labelled experiment is smaller indicating that the unlabelled version seems to better represent the data. To test whether this result is a significant improvement in fit, the likelihood ratio test can be applied (Bierlaire, 2003). The statistic to test whether the null hypothesis holds $\left(H_{0}\right.$ : the generic attribute specification has a better goodness of fit) is given by the following expression:

$-2\left(\operatorname{LL}\left(\beta_{\text {generic }}\right)-\operatorname{LL}\left(\beta_{\text {labelled }}\right)\right)$.

It is $X^{2}$ distributed with $\operatorname{LL}\left(\beta_{\text {generic }}\right)$ being the log-likelihood for the generic model and LL ( $\left.\beta_{\text {labelled}}\right)$ for the labelled one. Inserting the respective figures of Table 3 , the calculated value is $-2(-1246+1249)=-6.0$. The result is negative, and thus, does not exceed the $X^{2}$ value (3.84) at a $95 \%$ level of confidence (compare Bierlaire, 2008). Consequently, the labelled specification of the multi-nomial logit model does not lead to a significant improvement in fit.

\subsection{Nested-logit model}

One crucial assumption for the application of a multi-nomial logit model is that the random variable follows an identical and independent distribution (iid). This assumption is not fulfilled in case that unobserved similarities between options exist. As explained above such similarities might be based on time-related or aesthetical characteristics of the alternative protection measures. Therefore, in an additional analysis a nested-logit approach has been applied with the wooden and steel options in two separated nests in order to test, whether this specification is more appropriate.

The results are shown on the right hand side in Table 2. The nesting parameter $\mu$ is significantly different from 1 , indicating that the nest specification is valid. Additionally, according to the likelihood ratio test data fit has improved significantly $(-2(-1246+1244)=4.0)$, so that the nested logit model with wooden and steel alternatives in separated nests represents the superior model for our case study. The values and signs of the estimated coefficients are similar to the labelled multinomial model. Resulting differences can be explained in the context of the following willingness-to-pay analysis.

\subsection{Willingness-to-pay estimates}

One aim of the study was to determine the willingness to pay for avalanche protection services. Therefore, the monetary attribute "costs" has been included in the choice set design, which permits WTP calculations for protection measures but also for the other attributes by building the ratio of the respective coefficients (compare Eq. 15). In Table 3 results are shown for the attributes "damage avoidance", "project duration" and "starting time" and the different "types". The 
Table 2. Test statistics for unlabelled and labelled model specifications. MNL= Multinomial Logit; NL=Nested Logit.

\begin{tabular}{|c|c|c|c|c|c|c|c|c|c|c|c|c|}
\hline & \multicolumn{4}{|c|}{ Unlabelled } & \multicolumn{8}{|c|}{ Labelled } \\
\hline & \multicolumn{4}{|c|}{ MNL } & \multicolumn{4}{|c|}{ MNL } & \multicolumn{4}{|c|}{ NL } \\
\hline & Value & Std err & $t$ test & $p$ value & Value & Std err & $t$ test & $p$ value & Value & Std err & $t$ test & $p$ value \\
\hline ASC Bridges & & & & & 0.2820 & 0.3310 & 0.85 & 0.39 & 0.0760 & 0.3190 & 0.24 & 0.81 \\
\hline ASC Grills & & & & & 0.8940 & 0.1220 & 7.35 & 0.00 & 0.7080 & 0.1210 & 5.86 & 0.00 \\
\hline ASC Nets & & & & & 0.9040 & 0.3320 & 2.73 & 0.01 & 0.6970 & 0.3190 & 2.18 & 0.03 \\
\hline ASC Stems & & & & & fixed & & & & fixed & & & \\
\hline Damage avoidance $(\beta 1)$ & 0.0110 & 0.0044 & 2.48 & 0.01 & 0.0112 & 0.0044 & 2.54 & 0.01 & 0.0093 & 0.0040 & 2.35 & 0.02 \\
\hline Duration $(\beta 2)$ & -0.0049 & 0.0045 & -1.10 & 0.27 & -0.0058 & 0.0046 & -1.25 & 0.21 & -0.0057 & 0.0044 & -1.30 & 0.19 \\
\hline Starting time $(\beta 3)$ & -0.1730 & 0.0186 & -9.31 & 0.00 & -0.1710 & 0.0186 & -9.18 & 0.00 & -0.1500 & 0.0187 & -7.98 & 0.00 \\
\hline Costs $(\beta 4)$ & -0.0024 & 0.0006 & -4.33 & 0.00 & -0.0025 & 0.0006 & -4.43 & 0.00 & -0.0023 & 0.0005 & -4.39 & 0.00 \\
\hline Type $(\beta 5)-$ Bridges & 0.8510 & 0.3260 & 2.61 & 0.01 & & & & & & & & \\
\hline - Grills & 0.9050 & 0.1210 & 7.47 & 0.00 & & & & & & & & \\
\hline - Nets & 0.2320 & 0.3250 & 0.71 & 0.48 & & & & & & & & \\
\hline - Stems & fixed & & & & & & & & & & & \\
\hline Nesting $(\mu)$ & & & & & & & & & 1.5200 & 0.2300 & 2.19 & 0.00 \\
\hline Observations & 1290 & & & & 1290 & & & & 1290 & & & \\
\hline LL Init & -1417 & & & & -1417 & & & & -1417 & & & \\
\hline LL Final & -1246 & & & & -1249 & & & & -1244 & & & \\
\hline
\end{tabular}

Table 3. Willingness to pay for a change in attribute levels and types. MNL= Multinomial logit; NL= Nested logit; $n$.a. $=$ not available.

\begin{tabular}{|c|c|c|c|c|c|}
\hline \multirow[t]{3}{*}{ Attribute } & \multirow[t]{3}{*}{ Ratio } & \multicolumn{3}{|c|}{ Model specification } & \multirow[t]{3}{*}{ Units (in USD) } \\
\hline & & \multirow{2}{*}{$\begin{array}{r}\text { Unlabelled } \\
\text { MNL }\end{array}$} & \multicolumn{2}{|c|}{ Labelled } & \\
\hline & & & MNL & NL & \\
\hline Damage avoidance & $-\beta 1 / \beta 4$ & 4.51 & 4.46 & 3.96 & per $\%$ damage avoidance \\
\hline Duration & $-\beta 2 / \beta 4$ & -2.02 & -2.29 & -2.44 & per year duration increase \\
\hline Starting time & $-\beta 3 / \beta 4$ & -70.90 & -68.13 & -64.10 & per year starting time delay \\
\hline Type - Bridges & $-\beta 5(\mathrm{~B}) / \beta 4$ & 349 & & & per protection type \\
\hline - Grills & $-\beta 5(\mathrm{G}) / \beta 4$ & 371 & & & per protection type \\
\hline- Nets & $-\beta 5(\mathrm{~N}) / \beta 4$ & 95 & & & per protection type \\
\hline - Stems & $-\beta 5(\mathrm{~S}) / \beta 4$ & n.a. & & & per protection type \\
\hline
\end{tabular}

findings demonstrate that WTP estimates substantially depend on the model specification. Concerning the degree of damages avoided, the highest WTP of USD 4.51 (\% of damage reduction) results from the generic MNL model, while the labelled multinomial and nested approaches lead to a WTP that is by one to $10 \%$ lower, respectively. Note that, based on this calculation, WTP for a $100 \%$ damage avoidance would add up to about USD 400-450 per household.

The coefficient of the attribute "starting time" is negative, which means that early protection is preferred and reducing waiting time until protection measures are established has a positive impact on utility. WTP for such a reduction is again highest (about USD 71 per year) with the generic and lowest (USD 64 per year) with the nested approach, denoting a difference of about $10 \%$. A remarkable difference is related to "project duration": while WTP is negative for all specifications, both labelled models generate values that are about 10 to $20 \%$ higher compared to the generic model. However, in none of the models has the respective coefficients passed the $t$ test, indicating that they are not significantly different from zero. Concerning the categorical attribute "type", WTP for wooden grills is highest, followed by steel bridges and steel nets (though not significant).

\section{Discussion and conclusions}

Advantages and disadvantages of labelling in CE are subject of an on-going discussion in environmental CE literature and beyond (Blamey et al., 2001; de Bekker-Grob et al., 2010; Doherty et al., 2011; Itaoka et al., 2006; Jacobsen et al., 2008). This study aims at determining the impact of labelling on WTP estimates related to natural hazard protection. The presented results raise several questions, which are discussed in the context of the current discourse.

\subsection{Scope effects}

Czajkowski and Hanley (2009) emphasise the possible impact of labels on the scope effect in choice experiments, especially when related to biodiversity conservation. In this respect, Jacobsen et al. (2008) warn that respondents might 
confound different protection measures, e.g. habitat and biodiversity protection. Furthermore, Czajkowski and Hanley (2009) argue that willingness to pay might not only depend on the physical characteristics of a good but also on the alternative-specific label under which the good is presented, and they state that labels "may be an implicit but un-identified component of WTP" (Czajkowski and Hanley, 2009). In case that this implicit value is relatively high, the sensitivity of welfare estimates towards variations in the scope of environmental changes might be reduced.

The present study aims at valuing attributes of avalanche protection measures. In order to avoid scope effects a wellspecified scenario has been developed, where it is assumed that an existing and delimited protection forest had partly been destroyed by a wind throw. Additionally, relevant attributes have been identified that are of crucial importance for restoring the protection function. As a result, only $5 \%$ of the households found the questionnaire "incomprehensible" or "partially incomprehensible", and $2 \%$ assessed the selected scenarios as "unrealistic" (Olschewski et al., 2012). Therefore, it can be concluded that, in the present survey, avalanche protection has been presented as a locally and temporally well specified good, and consequently, insensitivity to scope was not likely to occur.

\subsection{Cognitive processing}

Hensher et al. (2005) point out that the decision to use labels or not should be made in the specific research context. However, they emphasise that unlabelled experiments using generic option titles, such as A, B and C, have several advantages. On the one hand they do not call for an identification and specification of each single alternative. On the other hand unlabelled experiments are supposed to avoid the problem that a label might just act like an additional attribute of a certain option. This can have an impact on the respondents' choice, when the label and the other attributes are perceived as interdependent. In this case the restrictive assumption of the basic multinomial logit model concerning the random component of the utility function is no longer met, which in consequence requires a change in the underlying behavioural model (Train, 2003).

A possible advantage of labelling could be seen in the design of more realistic choice sets, taking into account that respondents usually do not decide among generic alternatives when making consumer decisions (Hensher et al., 2005). In this context, labelled experiments are advantageous for estimating alternative-specific parameters. Labels might enable respondents to better embed their choices in the relevant policy context, as for example decisions on alternative avalanche protection measures in the present study.

This argument is related to evidence that respondents might have different cognitive processing strategies for given alternatives (Doherty et al., 2011), and has given rise to conduct the in-sample comparison with varying model specifi- cations. However, a caveat of this analysis might be seen in the switch from the labelled to unlabelled version only after the survey has been conducted. Alternatively, one might have thought of splitting the sample right from the start, where the labelled version of the choice experiment is presented to one group of respondents while the other has to choose among generic options. However, in this specific case the overall number of households was relatively small, which impeded the splitting of sample. For the same reason, determining heterogeneous preferences among households (Swait, 2006) or analysing possible impact of applied visualisation techniques on WTP (Olschewski et al., 2012) was omitted.

\subsection{Attribute attention}

Blamey et al. (2000) argue that labelling might reduce the attention that respondents pay to the different attributes presented. They observed that willingness to pay for attributes was lower in the labelled specification than in the generic version. The findings of the above presented in-sample comparison correspond to their results: when perceived as a labelled experiment, WTP is lower for both (i) the reduction of a starting time delay and (ii) the increase of avoided damages, while the (negative) WTP for longer project duration is higher in the labelled case but not significant in any of the model specifications. Concerning the WTP for different types of protection measures a comparison between labelled and unlabelled settings is not possible, given that "type" has been omitted as categorical attribute in the labelled specification, and served as a label instead.

\subsection{Informational content}

The results of the present study shed some light on a further aspect: the improved utilisation of information and data output, which would otherwise have been neglected. Labelling can contribute to a comprehensive interpretation of results, and the alternative specific constants permit a complementary comparison of different protection measures. The presented stepwise approach has the advantage to gradually check data fit, thereby didactically demonstrating an operational way of dealing with different model specifications. By testing these specifications and taking into account the information gathered through supporting survey questions, it is possible to identify the model with an improved goodness of fit and the most comprehensive content of information. This procedure can easily be adapted and applied to the valuation of protection measures against other natural hazards, such as flooding or rock fall. Advanced readers interested in testing techniques that go beyond the presented approaches are referred to Kanninen (2006), Louviere et al. (2000), and Train (2003). 


\subsection{Practical relevance}

In mountainous regions, protection services of forests are crucial to prevent the local population from natural hazards. In this study, people's preferences for protection in general, as well as for specific protection measures have been determined using a choice experiment. While the unlabelled specification indicates the highest WTP for grills and bridges, the labelled experiment comes to the conclusion that grills and nets are preferred. These partly contradicting findings call for a cautious interpretation of the results and highlight the importance of an adequate study design and model specification in advance. Further, it is recommended to refrain from rash generalisation and inadequate regional or national upscaling based on locally gathered data. As a moderate general conclusion in the present case, it can be stated that wooden grills are the preferred alternative, whereas wooden stems are least desired no matter which specification is chosen.

The WTP for protection against avalanches in general adds up to USD 400-450 per household (compare Sect. 3.4). The estimated lump-sum payments can be compared with the discounted costs of (i) maintaining the forest and its protective function by silvicultural measures of about USD 20 per household or (ii) establishing alternative technical measures of about USD 60 for stems, USD 200 for grills, and USD 600 for steel solutions (Olschewski et al., 2012). The comparison shows that WTP exceeds the costs of silvicultural measures and wooden grills, while the costs of steel bridges and nets would be covered only partly. This finding holds for all model specifications and indicates that the derived estimates are relatively robust no matter which model is applied.

Further, wooden grills have been identified as those technical measures preferred by the population in cases where the protection forest was destroyed. In contrast wooden stems are neglected in spite of their attractiveness related to aesthetical aspects (compare Sect. 2.3). Interestingly, these findings are in line with expert opinion about appropriate protection strategies, and demonstrate the population's awareness of and acquaintance with local natural hazards. The results contribute to a comprehensive assessment of protection measures and help to identify efficient solutions based on the judgement of the people potentially endangered by natural hazards.

Acknowledgements. The study has been financed by the Swiss State Secretariat for Education, Research and Innovation (SERI) within the framework of the EU-Cost Action E45 (EUROFOREX). I am thankful to all participants in the project, especially to my colleagues P. Bebi, A. Grêt-Regamey, M. Teich and U. Wissen Hayek for their cooperation and support, and to the municipality and inhabitants of Andermatt $(\mathrm{CH})$.

Edited by: H. Kreibich

Reviewed by: S. Fuchs, A. Lanorte, and two anonymous referees

\section{References}

Alberini, A., Longo, A., and Veronesi, M.: Basic statistical models for stated choice studies, in: Valuing Environmental Amenities using Stated Choice Studies, edited by: Kanninen, B. J., Springer Series: The Economics of Non-Market Goods and Resources A Common Sense Approach to Theory and Practice, Springer, Dordrecht, NL, 203-228, 2006.

Bennett, J. and Adamowicz, V.: Some fundamentals of environmental choice modelling, in: The choice modeling approach to environmental valuation, edited by: Bennett, J. and Blamey, R., Edward Elgar, Cheltenham, UK, 37-69, 2001.

Bierlaire, M.: An introduction to BIOGEME Version 1.6, available at: http://www.biogeme.epfl.ch, last access: 22 January 2013, 2008.

Bierlaire, M.: BIOGEME: A free package for the estimation of discrete choice models, Proceedings of the 3rd Swiss Transportation Research Conference, Ascona, Switzerland, available at: http//www.biogeme.epfl.ch, last access: 22 January 2013, 2003.

Blamey, R. K., Bennett, J. W., Louviere, J. J., Morrison, M. D., and Rolfe, J.: A test of policy labels in environmental choice modelling studies, Ecol. Econ., 32, 269-286, 2000.

Blamey, R. K., Louviere, J. J., and Bennett, J. W.: Choice set design, in: The choice modeling approach to environmental valuation, edited by: Bennett, J. and Blamey, R., Edward Elgar, Cheltenham, UK, 133-156, 2001.

Chrzan, K. and Orme, B.: An overview and comparison of design strategies for choice-based conjoint analysis, Sawtooth Software: Research Papers Series, pp. 18, available at: http://www. sawtoothsoftware.com, last access: 22 January 2013, 2000.

Czajkowski, M. and Hanley, N.: Using labels to investigate scope effects in stated preference methods, Environ. Resour. Econ., 44, 521-535, 2009.

de Bekker-Grob, E. W., Hol, L., Donkers, B., van Dam, L., Habbema, J. D. F., van Leerdam, M. E., Kuipers, E. J., EssinkBot, M. L., and Steyerberg, E. W.: Labeled versus unlabeled discrete choice experiments in health economics: An application to colorectal cancer screening, Value Health, 13, 315-323, 2010.

Doherty, E., Campbell, D., Hynes, S., and van Rensburg, T.: The effect of using labelled alternatives in stated choice experiments: an exploration focusing on farmland walking trails in Ireland, Paper for the Second International Choice Modelling Conference Annual Conference, Oulton Hall, 4-6 July 2011.

Green, P. and Srinivasan, V.: Conjoint analysis in marketing: New developments with implications for research and practice, J. Marketing, 54, 3-19, 1990.

Grover, R. and Vriens, M. (Eds.): The Handbook of Marketing Research, Sage Publication, Thousand Oaks, CA, 707 pp., 2006.

Hensher, D. A., Rose, J. M., and Greene, W. H.: Applied Choice Analysis - a primer, Cambridge University Press, Cambridge, UK, 717 pp., 2005.

Hoyos, D.: The state of the art of environmental valuation with discrete choice experiments, Ecol. Econ., 69, 1595-1603, 2010.

Huber, J. and Zwerina, K. B.: The importance of utility balance in efficient choice designs, J. Marketing Res., 33, 307-317, 1996.

Itaoka, K., Saito, A., Krupnick, A., Adamowicz, W., and Taniguchi, T.: The effect of risk characteristics on the willingness to pay for mortality risk reductions from electric power generation, Environ. Resour. Econ., 33, 371-398, 2006. 
Jacobsen, J. B., Boiesen, J. H., Thorsen, B. J., and Strange, N.: What's in a name? The use of quantitative measures versus "iconised" species when valuing biodiversity, Environ. Resour. Econ., 39, 247-263, 2008.

Kanninen, B. J. (Ed.): The Economics of Non-Market Goods and Resources - A Common Sense Approach to Theory and Practice, Springer Series, Springer, Dordrecht, NL, 2006.

Krupnick, A. and Adamowicz, W. L.: Supporting questions in stated choice studies, in: Valuing Environmental Amenities using Stated Choice Studies, edited by: Kanninen, B. J., Springer Series: The Economics of Non-Market Goods and Resources A Common Sense Approach to Theory and Practice, Springer, Dordrecht, NL, 43-66, 2006.

Leiter, A. M. and Pruckner, G. J.: Proportionality of willingness to pay to small changes in risk: the impact of attitudinal factors in scope tests, Environ. Resour. Econ., 42, 169-186, 2009.

Louviere, J. J.: Choice experiments: an overview of concepts and issues, in: The choice modeling approach to environmental valuation, edited by: Bennett, J. and Blamey, R., Edward Elgar, Cheltenham, UK, 13-36, 2001.

Louviere, J. J., Hensher, D. A., and Swait, J. D.: Stated choice methods - analysis and application, Cambridge University Press, Cambridge, UK, 402 pp., 2000.
Olschewski, R., Bebi, P., Teich, M., Wissen Hayek, U., and GrêtRegamey, A.: Forest avalanche protection - Methods and results of a willingness to pay analysis, Swiss Forestry Journal, 162, 389-395, 2011.

Olschewski, R., Bebi, P., Teich, M., Wissen Hayek, U., and GrêtRegamey, A.: Avalanche protection by forests - A choice experiment in the Swiss Alps, Forest Policy Econ., 15, 108-113, 2012.

Rheinberger, C. M.: Dealing with the white death: avalanche risk management for traffic routes, Risk Anal., 29, 283-249, doi:10.1111/j.1539-6924.2008.01127.x, 2009.

Sawtooth: Sawtooth Software, Technical Paper Series.: CBCv6.0 (Technical paper), 25 pp., 2008.

Swait, J.: Advanced choice models, in: Valuing Environmental Amenities using Stated Choice Studies, edited by: Kanninen, B. J, Springer Series: The Economics of Non-Market Goods and Resources - A Common Sense Approach to Theory and Practice, Springer, Dordrecht, NL, 229-293, 2006.

Train, K. E.: Discrete choice methods with simulations. Cambridge University Press, Cambridge, UK, 334 pp., 2003.

Wierenga, B.: Handbook of Marketing Decision Models, Springer, New York, USA, 625 pp., 2008. 